\title{
Using digitised medical journals in a cross European project on addiction history
}

\begin{abstract}
This article draws on research conducted as part of a European project on the changing terminology used to conceptualise habitual drug, alcohol or tobacco use. We wanted to find out what language was utilised in Italy, Poland, Austria and the UK and how those concepts had changed since the mid-nineteenth century. We intended to make use of digitised journals for key word searches to enable comparisons to be made across countries and across time.
\end{abstract}

Nothing, however, was straightforward. Few countries had digitised medical journals, so researchers had to use traditional search methods. Even in the UK, where journals were available digitally, there were problems with access and the searches that could be made.

Digitisation did not provide a quicker way of researching cross nationally. Nonetheless our work did arrive at some valuable new conclusions. Our experiences also raise wider questions about using digitised journals for historical research.

\section{Introduction}

In recent years much ink (both real and electronic) has been spilled on the opportunities and drawbacks presented by the digitisation of historical sources. Previously hard to obtain resources have been made more accessible and new 
tools, such as text mining, allow researchers to conduct searches in minutes rather than over many months or years. Published sources like newspapers and periodicals are some of the most commonly digitised sources, and the nineteenth century is a period that is particularly well served by digitisation projects. ${ }^{1}$ Whilst there are a plethora of possibilities offered by the 'digital turn', the revolution is far from complete, and there are many issues still to be resolved. ${ }^{2}$ In this article we explore some of the advantages and disadvantages of attempting to make use of digitised medical journals, especially when working cross-nationally. Drawing on research conducted as part of a European project on the changing terminology used to conceptualise habitual drug, alcohol or tobacco use, we highlight some of the problems presented by digitised sources but also point to ways in which this kind of research generated new and unexpected insights. Our findings were novel within the history of substance use, but also raise questions about digitisation projects and the ways in which historians make use of these.

This article is divided into three sections. We begin by detailing the wider project of which this research was part, and setting it the context of the existing literature on the history of substance use. Our findings come from work conducted as part of a European Union Framework Programme 7 funded project on addiction across Europe. The Addiction Lifestyles in Contemporary Europe: Reframing Addictions Project (ALICE RAP) brought together a range of researchers from different disciplines and European countries to address the problems associated with substance use and addictive behaviours. One of the ALICE RAP workpackages, 'Addiction Through the Ages', focused specifically on 
the history of addiction across Europe, a largely under-explored topic within the history of substance use. In the second section of the article, we discuss in more detail our methodology for researching the history of addiction in Europe during the nineteenth century, and the ways in which we attempted to make use of digitised medical journals. We encountered a number of problems, some of which were due to the sources themselves, but others were related to our crossnational focus. We found that digitisation programmes were not always so advanced in the other European countries within our project, forcing us to resort to more traditional search methods. Moreover, the changing nature of both our topic of research (the terminology surrounding drug, alcohol and tobacco use) and the fluctuating borders of the European countries we focused on, presented us with several moving targets. In the third section of the article we discuss some of the findings from our research. Our exploration of the language of addiction over the period 1860-1930 in different European countries (Austria, Italy, Poland and the UK) generated novel data, and goes some way to correcting an Anglo-American bias in the history of substance use. The research also threw up several interesting questions about doing digital research when working across different countries and time periods. We reflect on these issues in the conclusion, arguing that historians, archivists, librarians and funders need to work together to make sources available and usable for future generations of researchers.

The ALICE RAP Project: Addiction Through the Ages Across Europe 
The ALICE RAP project was a five-year research collaboration running from 2011-2016 with a vision 'to promote well being through a synthesis of knowledge to redesign European policy and practice to better address the challenges posed by substance use and addictive behaviours' ${ }^{3}$ The project was large, with seven broad areas and twenty-one workpackages. Over 200 researchers were involved from twenty-five countries and twenty-nine disciplines. The history workpackage was led by Professor Virginia Berridge. Findings from this research and other parallel projects have been published in several articles and collated in an edited volume on concepts of addictive substances and behaviours over time and space. ${ }^{4}$ The history workpackage was set up to involve a set of pre-existing partners from pre-selected European countries. Partners in this component of the workpackage came from the UK; Austria; Italy; and Poland. Although these case-studies countries were preselected (as part of the way the wider ALICE RAP project was designed) they represented a good mix of geography, comprising of countries from Western, Central, Southern and Eastern Europe, with different cultural attitudes towards, and histories of, substance use.

The core purpose of the history workpackage was to chart the changing terminology of addiction over the course of the period between 1860 and 1980 . A broad framework for the project was established before we began the research, and we developed a more specific programme of action once the research was underway. We began by breaking this period into three phases: the 1860s-1930s, the 1950s-1960s, and finally the 1970s-1980s. We chose these periods as the existing historiography suggested that these were eras 
when changes in the concepts used to describe substance use may have occurred. The late nineteenth and early twentieth centuries, (as we discuss in greater detail below) were a time when the concept of 'addiction' in relation to drugs and alcohol was established and elaborated. We thought that the period from the 1950s-1960s would also be of interest, as this was when international organisations, such as the World Health Organisation, began to play a role in describing and responding to addiction. Our final phase, from the 1970s to the 1980s, was a period when drug and alcohol problems grew in size and scale, and we wanted to see what impact this had on the terminology used to describe them.

But, as we shall see, we encountered a number of practical and conceptual difficulties in our attempt to used digitised sources. Although this may be of no surprise to experienced digital researchers, it is an important point to reiterate, as it raises wider questions about how non-experts in using digitised sources approach these and how these are used in conjunction with non-digitised material, especially when working cross-nationally.

Carrying out historical work on addiction across and within European countries was particularly important, as though there is a vibrant literature on drugs, alcohol and tobacco use, much of this is focused on the USA and the UK. With some notable exceptions, research has tended to centre on substance use in an Anglo-American context. ${ }^{5}$ A particular area of interest surrounds the emergence and development of the concept of 'addiction'. For some observers, such as the historian Jessica Warner, the modern disease-based concept of alcohol addiction first appeared in the seventeenth century. She contended that 
Stuart clergymen often described habitual drunkenness in terms of addiction.

Other historians, like Roy Porter, place the origins of the concept of addiction in the eighteenth century. ${ }^{6}$ A disease-based concept of addiction can be observed in the work of Benjamin Rush in America and Thomas Trotter in England towards the end of the eighteenth century. ${ }^{7}$ During the nineteenth century, the notion of addiction underwent significant change, as the growing forces of evangelism and urbanisation gave the concept of addiction new weight. The appearance of the temperance movement, and the need for doctors to explain the overwhelming desire for drink, helped to consolidate an understanding of addiction that located the problem in the drink rather than the drinker. The word 'alcoholism', first developed by Magnus Huss in Sweden, began to come in to use as a distinct term to describe disease-based understandings of compulsive alcohol use.

In the nineteenth century, disease-based understandings of addiction expanded to include other substances as well as alcohol. New and more potent drugs, more effective methods of administration and medical professional involvement, drove this development. Addiction came to be seen as a 'disease of the will', an understanding that combined both medical and moral elements. ${ }^{8}$ Such a view could be found in the arguments of temperance reformers and antiopium campaigners as well in the medical literature. This medico-moral alliance was part of a wider trend that saw other issues, such as madness and sexuality, in a similar light. All of this is not to say, however, that tension did not exist between medical and moral approaches. As Mariana Valverde has demonstrated, medico-moral discord meant that there was no universally agreed 
definition of addiction, and no universally accepted treatment for the condition either. ${ }^{9}$

Indeed, it is striking that during the nineteenth and twentieth centuries there were a range of terms in use to denote addiction to alcohol and other psychoactive substances. The term 'inebriety' features centrally within the Anglo-American literature of the time, a word that covered addiction to both drink and drugs. The development of the concept of inebriety was connected to the work of professional societies, such as the British Society for the Study and Cure of Inebriety, which was established in $1884 .{ }^{10}$ The notion of inebriety offered an alternative to the criminalisation of the drinker, allowing for the treatment, rather than the incarceration, of inebriates. Yet other words, like 'alcoholism', were also employed to describe habitual problems associated with substance use. What led to the emergence and development of these terms, and how did their usage and meanings change over the course of the nineteenth century and early twentieth century? Moreover, were these terms confined to the UK and the US, or were they used in Continental Europe too? How did imported concepts interact with the pre-existing domestic language to describe substance use? What were the origins of these terms, and how were they similar or different to the words used in the other countries within the study?

\section{Methodological challenges and approaches in researching the cross- national history of addiction concepts}


In order to answer such questions we agreed, together with our European partners, to design a common methodology to chart the changing terminology of addiction. For our first period (1860s-1930s), we agreed that we would focus on the medical approach to substance use, and make use of digitised medical journals where possible. ${ }^{11}$ For our second (1950s-1960s) and third (1970s1980s) periods we took a different tack. We decided to move away from the focus on medical texts to look at how addiction concepts were utilised within policy documents produced in these decades. ${ }^{12}$ All of the researchers in the different countries (Austria, Italy, Poland and the UK) agreed to adopt this common methodology, so that as far as possible our results would be comparable. We decided that this could be achieved by examining one general medical journal, one specialist addiction journal, and one medical textbook for each country. We knew that the medical textbooks were unlikely to be digitised, but we assumed naïvely that the digitisation of medical journals in the UK would make this part of the research relatively straightforward and quick to generate results both for the British study, and for our European partners. The full results of our research based on this approach are summarised elsewhere, but here we concentrate on the work we did with the medical journals. Based on the existing historiography, we collated a list of terms used to describe drug and alcohol use in English (Table 1), which we then intended to search for in the digitised medical journals. We wanted to count how frequently the different terms were used in the medical journals and plot any changes and continuities over time. We also wanted to see if these terms were translated into the different languages used in or study countries, or if these countries had their own terminology to describe drug and alcohol problems. 


\begin{tabular}{|l|}
\hline English Key Word Search Terms \\
\hline Habit \\
\hline Dipsomania \\
\hline Alcoholism \\
\hline Chronic Poisoning \\
\hline Morphinomania \\
\hline Narcomania \\
\hline Inebriety \\
\hline Morphinism \\
\hline Addiction \\
\hline
\end{tabular}

Table 1: English Key Word Search Terms

Operationalising this approach, however, proved more difficult than we thought. There were a number of issues around how to translate the search terms from English into the different European languages used in our study countries. For some terms, there was an obvious English equivalent: 'Alcoholism', for instance, could be translated into 'Alkoholizm' in Polish; 'Alkoholismus' in German and 'Alcolismo' in Italian. But even here there were differences, (as we explore in more detail below) in Austria 'Alkoholismus' did not enjoy the conceptual hegemony experienced elsewhere in Europe, as there was another set of terms around drink and the drinker that were also in use. Moreover, other words proved to be untranslatable, or local differences in meaning implied that terms 
could not be considered synonymous. 'Addiction' for example, could be

translated as 'Nałóg' in Polish, but the term could be used as both a noun and an adjective.

\begin{tabular}{|c|c|c|}
\hline Country & Terms used & English translation \\
\hline Austria & $\begin{array}{l}\text { Alkoholismus } \\
\text { Trunkenheit } \\
\text { Trunksuch } \\
\text { Gewohnheitsstrinker }\end{array}$ & $\begin{array}{l}\text { Alcoholism } \\
\text { Intoxication } \\
\text { Ailing due to drinking } \\
\text { Habitual drinker }\end{array}$ \\
\hline Italy & $\begin{array}{l}\text { Alcolismo } \\
\text { Avvelenamento da alcol } \\
\text { Delirium tremens } \\
\text { Dipsomania } \\
\text { Intossicazione alcolica } \\
\text { Psicosi alcoliche } \\
\text { Ubriachezza } \\
\text { Ubriachezza abituale } \\
\text { Ubriachezza patologica } \\
\text { Avvelenamento da } \\
\text { morfina } \\
\text { Morfinismo } \\
\text { Morfinodipsia } \\
\text { Morfinomania } \\
\text { Avvelenamento da } \\
\text { cocaina } \\
\text { Cocainismo } \\
\text { Intossicazione da cocaina } \\
\text { Avvelenamento da eroina } \\
\text { Avvelenamento da oppio } \\
\text { Intossicazione da nicotina } \\
\text { Intossicazione da tabacco } \\
\text { Nicotinismo }\end{array}$ & $\begin{array}{l}\text { Alcoholism } \\
\text { Alcohol poisoning } \\
\text { Delirium Tremens } \\
\text { Dipsomania } \\
\text { Alcohol intoxication } \\
\text { Alcoholic psychosis } \\
\text { Drunkenness } \\
\text { Habitual drunkenness } \\
\text { Pathological } \\
\text { drunkenness } \\
\text { Morphine poisoning } \\
\text { Morphinism } \\
\text { Morphine dipsomania } \\
\text { Morphinomania } \\
\text { Cocaine poisoning } \\
\text { Cocainism } \\
\text { Cocaine intoxication } \\
\text { Heroin poisoning } \\
\text { Opium poisoning } \\
\text { Nicotine intoxication } \\
\text { Tobacco intoxication } \\
\text { Nicotinism }\end{array}$ \\
\hline Poland & $\begin{array}{l}\text { Alkoholizm } \\
\text { Dipsomania, dypsomania } \\
\text { Kokainizm } \\
\text { Morfinizm } \\
\text { Nałóg } \\
\text { Nałogowy pijak } \\
\text { Narkomania } \\
\text { Nawyk } \\
\text { Nikotynizm } \\
\text { Opilstwo } \\
\text { Pijaństwo } \\
\text { Tytomania }\end{array}$ & $\begin{array}{l}\text { Alcoholism } \\
\text { Dipsomania } \\
\text { Cocainism } \\
\text { Morphinism } \\
\text { Addiction } \\
\text { Addicted drunkard } \\
\text { Drug addiction } \\
\text { Habit } \\
\text { Nicotinism } \\
\text { Inebriety } \\
\text { Drunkenness } \\
\text { Tobacco addiction }\end{array}$ \\
\hline
\end{tabular}


Table 2: Terms used to describe drug \& alcohol use in European study countries

There were practical problems too. We thought that each country would have its own general medical journal, and a more specialist publication devoted to drug and alcohol use (as in the UK). This was not the case in any of our Continental European focus countries. In Italy, there was no general medical journal in this period, so the researchers had to focus on more specialist publications, particularly in forensic science. ${ }^{13}$ In Poland, researchers could not find a specialist journal that dealt with substance use, but there were two general medical journals, one that was published weekly and another monthly. Records of the monthly journal, however, were incomplete, especially during the period of the Polish-Soviet War (1918-21). ${ }^{14}$ In Austria, the situation was further complicated by the fact that the language used did not coincide with the national border. German was the language of the republic as well as the Empire, and spoken in the neighbouring countries where most of the medical journals were published. ${ }^{15}$

\begin{tabular}{|l|l|}
\hline Country & Journals Used \\
\hline Austria & $\begin{array}{l}\text { Wiener Medizinische Wochenschrift } \\
\text { (general medical journal); }\end{array}$ \\
\hline
\end{tabular}




\begin{tabular}{|l|l|}
\hline & $\begin{array}{l}\text { Jahrbücher für Psychatrie/ Jahrbücher } \\
\text { für Psychiatrie und Neurologie } \\
\text { (specialist psychiatritc journal) }\end{array}$ \\
\hline Italy & Archives of Criminal Anthropology, \\
& Psychiatry, Forensic Science and \\
& related Science; Experimental Journal \\
& of Psychiatry and Forensic Science of \\
& the Mental Alienation; Journal of \\
& Forensic Science; Journal of Forensic \\
& Science; Journal of Forensic Science and \\
& Medical Jurisprudence (all forensic \\
& science journals) \\
\hline Poland & Gazeta lekarska (Physician's Gazette); \\
& Nowiny lekarskie (Medical News) (all \\
general medical journals)
\end{tabular}

\section{Table 3: Journals used by country}

More fundamentally, few of the European journals had been digitised. When we began the project none of them had, but during the course of our research some of the Polish journals became available digitally, although these were incomplete with large gaps. So, our European colleagues largely had to rely on hand sorting and counting to locate addiction terminology. Not only was this much more time consuming (a significant issue when a fixed amount of time and resources could be devoted to the research) but it also required the research teams in the different countries to take slightly different approaches. The Austrian researcher decided that a differentiation needed to be made between the use of addiction terms in 'short' and 'main' articles; the Italian team used the journal index and contents pages to identify relevant articles, and then counted the number of addiction terms used within these articles; the Polish team counted the number of 'units' (articles, letters, short reports and notes) that 
referred to substance use and the different terminology used. ${ }^{16}$ Specificities in each of the countries within the study thus resulted in a dilution of the common research method. This made direct comparison between the different countries more difficult, but general trends did emerge.

Even in the UK, where digital versions of our chosen sources - the British Medical Journal (BMJ), The Lancet and the British Journal of Inebriety - were obtainable, there were problems. The journals were all digitised, with searchable online archives and articles available as pdf. files. But, to our surprise, this did not necessarily mean ease of access and analysis. Each journal was available under a different licensing agreement and this constrained our ability to conduct keyword searches. The British Journal of Inebriety required a user subscription, whilst full-text electronic access to the Lancet was only available onsite at two libraries. The BMJ and Lancet covered the whole of our time period from 1860 to 1930 , but only post-1904 search results could be obtained for the British Journal of Inebriety. The journal's predecessor, Proceedings, was available as scanned (jpeg.) images, but this prevented comparable electronic searches without the aid of text recognition software and analysis could only be done on a page by page basis, a very laborious activity.

Once we had access, using the digitised sources to conduct the keyword searches also proved to be problematic. The way in which some of the journals had been digitised and made available impeded our research. For example, the default search option with some sources included all a publisher's titles rather than allowing a search within a specific time frame and journal. Creating a search that focused on just one journal was complicated and laborious as the 
other journals needed to be manually filtered out. Furthermore, it was not always possible to sort search results in order. This posed a particular challenge for terms that produced a large amount of results. Key-word searches within electronic articles were also inconsistent, and sometimes failed to capture terms within the text, especially when the file resolution was poor. Our chosen search terms also caused some difficulties. Words like 'habit' could be applied in many contexts, thus generating false positives in the results. Furthermore, the inclusion of 'inebriety' in a journal name, and the widely documented creation of the 'Society of the Study of Inebriety' (1884) both presented further difficulties, over emphasising the use of the term. Finally, certain words yielded insufficient data, which impeded attempts to chart their changing usage over time, or to make meaningful comparisons with how and when they were used in the other literature. Digitisation, then, was not a route to the quick and easy generation of results.

\section{Addiction Terminology in Europe, 1860s-1930s}

Despite these many difficulties, we were able to acquire some useful data and use this to gain a new insight into addiction and its terminology in Europe during the period 1860-1930. Overall, the research showed considerable divergences between countries in this period but also some significant points of convergence. We will summarise the results of our work in this period by country and then discuss them overall. ${ }^{17}$ In the UK, the digital searches showed very clearly the rise and predominance of the concept of inebriety in the medical arena from the 1870s. There were, for instance, 4 uses of 'inebriety' in the $B M J$ in 1878 , rising to 
32 by 1890 . Further periods of extensive debate occurred in the 1900 s, at a time of discussion of the extension of inebriates legislation and concerns about national degeneration. Usage of 'inebriety' peaked in 1902 in the Lancet and 1914 in the $B M J$, with just less than 90 usages of the term in each journal in each year. But the term fell out of favour at the time of the First World War and was rarely used thereafter. Two terms began to replace the unified inebriety concept. One was 'alcoholism' and the other was 'addiction'. The former term began to rise in prominence from the late nineteenth century but it did not achieve acceptability in the way in which 'drug addiction' did and declined after the First World War, perhaps in line with reduced interest in alcohol as a social issue in the inter-war years. The term 'alcoholism' was used 11 times in 1884 in the $B M J$, rising to a peak of 88 times in 1914, but fell rapidly after this so that the term only occurred 9 times by 1919. 'Addiction', however, began its rise after 1918. The term was virtually unused before this date, but incidences of usage increased rapidly. By 1922 it occurred seven times in the $B M J$ and 16 times by 1927.

These patterns were representative of a significant divergence from ways of describing habitual substance use in the past. 'Inebriety' was a term that had encompassed alcohol and other drugs within the same framing applying to both sets of substances but with a particular emphasis on alcohol. 'Addiction', however, was not a combined term and the connection between 'addiction' and 'drug' is clearly demonstrated in the figures. The ascent of addiction occurred against a backdrop of continued use of a mix of terms and common interchange of, for example, 'morphinism', 'morphine habit' or 'morphinomania' within the 
medical texts surveyed. This was clearly a period of flux in agreed terminology but the general trends - the rise and decline of inebriety and the rise of addiction focussed on drugs other than alcohol - were clear. Through the British Society for the Study of Inebriety and its medical membership, the terminology was 'owned' by a clearly defined medical group. ${ }^{18}$

In the three other European countries, however, the picture differed. Unlike the UK, none had a substantial tradition of historical research and debate on alcohol, tobacco and other drugs, and so our work was breaking new ground in many ways. In Italy, there was rising interest in specifically alcohol related issues in this period - seven articles between 1860 and 1889, increasing to 45 in the 1890-1909 time span, and finally 71 between 1910 and 1930 . Terms also proliferated - including 'alcoholic psychosis', 'alcoholic paranoia', 'pathological drunkenness', and 'delirium tremens'. There was a expansion in the number of terms at the same time as their use was increasing, but the most used concept was 'alcoholism'. Concepts used to characterise other drugs were concentrated at the turn of the nineteenth century (1895-1905) and in the 1920s, but were much more sporadic in their appearance. The terms were divided in a similar way between those concerned with physiological aspects such as 'morphine and cocaine poisoning', and those that deepened the pathological issues, like 'morphinism', 'cocainism' or 'morphinomania'. A major difference between Italy and Britain came in the professional ownership of the issue. ${ }^{19}$ In Italy, the experts interested in substance use were part of the school of positivist criminology associated with the work of Cesare Lombroso. In the UK, alcohol 
and drug issues were dealt with by medical professionals, not criminologists, although like Italy, some of these doctors were influenced by hereditarian ideas.

In Austria, there were further differences. Here it seems that two sets of terminology existed in relation to alcohol and to a lesser extent for other drugs. At first sight the terminology clustered around the words 'alcohol' and 'alcoholism'- with parallel terms 'morphine' and 'morphinism'. At second sight the local terminology - the German dialect used in Austria - proved to be of comparable importance: it clustered around traditional German expressions about the intake of intoxicating substances - 'trinken' (drink) - and of its main effects - being 'trunken' (drunken). 'Alcohol' and 'alcoholism', to contemporary understanding, were foreign words and not part of the local terminology (Ausdrucksweise). The assumption that the two terminologies indicated more than one addiction concept was supported by the preference of the legal discourse for the German terminology until the present day and by the twofold addiction concept used in contemporary Austrian psychiatry. The final list included names of substances and verbs for intake and was divided between two families or clusters: the international one was based on 'alkohol' (alcohol), 'alkoholiker' (alcoholic) and 'alkoholismus' (alcoholism), the local on 'trinken' and 'trunken'. Both included combinations with core words and derivatives such as 'trinker' (drinker), 'trinksitte' (drinking customs), 'trinkerrettung' (salvation of drinker), 'trunkenheit' (intoxication), 'trunkenbold' (drunkard) and 'trunksuch' (ailing due to drinking).

Analysis of the language used in the Austrian articles reinforced the impression of the existence of two terminologies and of more than one addiction 
concept: the international terminology was linked to a scientific concept of addiction with one main cause - drinking - and with universal (harmful) consequences, which, after the turn of the century, increasingly included hereditary degeneration. The German terminology conceived trunksucht (ailing because of drinking) as an incurable secondary disease of a mental disorder and at the same time as the curable consequence of passion. Both types of addiction were loosely united in one concept, but though the first type was increasingly amalgamated with the scientific concept, the latter could neither penetrate nor replace the local concept used by German speaking Austrians. ${ }^{20}$

In Poland, most of the key words used in our search appeared more or less frequently in the whole period under study, though their meaning or range underwent change. 'Alcoholism', 'drunkenness', 'poisoning', (including chronic and acute) and 'inebriety' were the terms most frequently in use. Dipsomania' appeared rather seldom, as did 'habit'. The term 'nałóg', which linguistically could be a concept close to addiction, was very rare indeed and used as an adjective as well as a noun. The term 'alcoholism' was used increasingly and at the expense of other terms, in particular that of 'inebriety' which, as in the UK, almost disappeared from the medical debate at the beginning of the twentieth century. During this period in Poland, illicit drugs were of secondary importance in the addiction vocabulary. The concept of drug 'addiction' appeared a decade later than the debate on alcoholism - in the 1880 s as opposed to the 1870 s instead the literature adopted the similar concepts of morfinizm and kokainizm as the major terms relating to drug addiction. 
In Poland, our more detailed conclusions were restricted to alcohol addiction as this terminology appeared with sufficient frequency. Initially, in the 1860s, 'inebriety' or 'drunkenness' were perceived as a source of mental disorder due to alcohol's poisonous impact on the human brain but these terms evolved to become 'alcoholism' - a mental disease in its own right - towards the end of the nineteenth century. The concept of alcoholism as an artificially induced madness was also elaborated. This 'artificial insanity' could be shortterm (acute) as long as the influence of alcohol lasted, or chronic if inebriety persisted to become a permanent state. At the beginning of the twentieth century, the concept of alcoholism changed again from referring only to the mental disease, to cover all the somatic and mental consequences for the affected individual. Later, in particular after Poland regained its independence, these medical overtones were replaced by social concerns. The term 'alcoholism' tended to cover all medical and social consequences, including major social conditions such as poverty and crime. In addition to medical treatment, temperance and prohibition solutions were discussed. But at the same time, alcoholism was increasingly interpreted as an expression of the individual degeneration of alcoholics and their offspring and, therefore, individual, eugenic control became a solution which was seriously considered. Addiction in general was a concept owned mostly by psychiatrists. That situation changed in the twentieth century when public hygiene and social welfare experts joined psychiatrists, paying attention to the social aspects of addiction and seeking solutions in social interventions. ${ }^{21}$ 
This brief survey shows that the Anglo-American inebriety model was by no means transferable wholesale to our emergent understanding of concepts in selected European countries in this period. Some countries, such as Poland, did use the terminology of inebriety (restricted to alcohol only) but it was not universal elsewhere in our study. This was a period of flux in language with a multiplicity of terms in use, gradually moving towards some degree of greater standardization by the end of our period. But a country such as Austria, still maintained a localized language in relation to drunkenness as well as the more international terminology of alcoholism and addiction. It would be interesting to see the extent to which this pattern, particularly around the use of terms related to 'drunkenness', was replicated elsewhere. Different professional traditions of ownership were also apparent, most notable the role of forensic scientists and the influence of Lombrosian criminology in Italy. These will be a fruitful lines of future research that we were unable to pursue here.

There were also some factors and issues in common across our study nations. In all countries, this was a period when interest was rising in these topics and alcohol was initially the dominant substance with other drugs emergent as a separate subject of discussion by the turn of the century, gathering pace around the time of the First World War and afterwards. Although individual country traditions remained strong, two significant areas showed similarities. One was the common interest in theories of heredity at the turn of the nineteenth and twentieth centuries: concern about the 'deterioration of the race' seems to have been a cross-national and perhaps Europe-wide phenomenon. In England, the involvement of alcohol as a 'race poison' in the 
eugenic debate on national deterioration is well known. ${ }^{22}$ The same was the case in other European countries. In Italy, the effect of alcoholism on heredity was frequently quoted. ${ }^{23}$ There were similar discussions in Poland and Austria. The influence of such eugenic thought is also a partial explanation of what seems to be another commonality - the growing interest in a 'social' view of alcohol issues in the early twentieth century and in the period after the First World War. In several countries, England for example, and Italy as well as in Poland, there were debates between hereditarian, individualistic positions and more social, problem and poverty focused ones. For instance, in 1919, the Polish Deputy Minister for Public Health asserted that alcoholism was a social disease that could only be cured by physicians and social activists working together. ${ }^{24}$

The other, and related, commonality was evidence of an emergent community of knowledge across these European countries. Most country studies indicated that there were cross-national influences by way of scholars citing other international authors, reviews of books and other means. For example, in Italy, one author, Zerboglio, took the work of Krafft-Ebing and Huss as his reference. ${ }^{25}$ In England, the work of the German authority Eduard Levinstein on morphine addiction was widely cited. In Poland, the psychiatrist Frydrych was influenced by a journey in Europe and cited the Swedish physician Magnus Huss and the French psychiatrist Bénédict Morel. In-depth discussion of this interest is not possible here since the major focus of our work was quantitative rather than qualitative. But, it appears to relate to the existing European discussion and elaboration of theories of insanity that also utilized these authorities. These panEuropean intellectual influences seem to have been just as influential as the 
expected role of the temperance movement. This was of key importance in some countries, the UK for example, where medical temperance supporters played a leading role in the professional society. Doctors were also involved in the Austrian temperance movement as they were in Italy.

The period 1860-1930 was thus one of great flux across Europe with respect to the concepts used to describe drug and alcohol use. No single concept or concepts appeared to dominate, and though 'alcoholism' was used in all of the countries studied it did not necessarily mean the same thing. Local discourses, such as that around drink and the drinker in Austria, still had a role to play.

\section{Conclusion}

The ability to discern similarities and differences between countries over time is something that can only come from cross-national comparative work. To what extent can digitisation help or hamper this kind of endeavour? Where digital sources exist, these can be extremely useful. We found that for the UK, our digital source base allowed us to identify patterns easily, and also to find things that we did not expect - like the temporary decline in the use of the term 'alcoholism'. This kind of research was thus very good at demonstrating change and continuity over time. Making use of digitised journals was, at least in theory, quicker than drawing on traditional paper sources, and certainly was less time consuming for the UK team than for some of our European partners who had to do hand searches and counts. Ironically, digital source research could be particularly valuable in these very places: in the UK we are blessed with an 
extensive historiography on drugs and alcohol, whereas in many European countries this is not the case. Searching digital sources for the use of key terms and concepts could provide a quick and easy way to generate a narrative of change and continuity over time for topics and places about which little is known. Such research could then provide a springboard to deeper analysis.

Caution, however, should be exercised, as digitisation does not offer a panacea. For our project, the limited availability of digital sources for our European partners made this aspect of the work particularly challenging. It may be that digitisation projects grow in European countries in the coming years, but this will take time, resources and commitment. The limited availability of digital resources in certain countries must not be allowed to hamper the kind of comparative work that is done, or else existing patterns could be reinforced. In the case of drugs and alcohol, for instance, the relative ease in which British and American sources can be accessed could consolidate the Anglo-American bias in the literature. At the same time, the increased availability of digital sources will encourage more researchers to make use of these, often without an awareness of the advantages and disadvantages these present, or of the particular methodological and technological tools one can use to deal with these. For instance, we encountered a number of technical issues that made searching problematic. The differing formats and ways of accessing publications make it hard to adopt a universal research design and the piece-meal approach that develops as a result can further hamper comparative work.

Some of these problems might have been resolved by using text mining tools and other digital analysis software. Text mining, however, also has its 
pitfalls. For example, it has been argued, using the results of text mining the digitised London Medical Officer of Health reports, that interwar public health was moving away from a focus on 'moral ills' to a less judgmental stance and a greater focus on prevention. The decline in the frequency of the word 'alcoholism' was one result used to make this point. ${ }^{26}$ Our research showed that this decline was only temporary. During and after World War Two, alcoholism was established as the dominant concept. This example shows how digital results need to be triangulated with each other but also with traditional historical research and contextualization. Focusing only on terms and not the context in which they existed both on the page and more broadly risks missing the bigger picture. The digital age may require us to develop new skills and approaches, but it seems likely that we will also need analogue abilities for some years to come.

\section{Acknowledgments}

The research leading to these results or outcomes has received funding from the European Union's Seventh Framework Programme (FP7/2007-2013), under Grant Agreement no 266813 - Addictions and Lifestyle in Contemporary Europe Reframing Addictions Project (ALICE RAP - www.alicerap.eu). Participant organisations in ALICE RAP can be seen at www.alicerap.eu/about-alice$\underline{\mathrm{rap} / \mathrm{partners} . h \mathrm{tml}}$.

The views expressed here reflect those of the authors only and the European Union is not liable for any use that may be made of the information contained therein. 


\section{Notes}

${ }^{1}$ Mussell, "Nineteenth-Century Newspapers in the Digital Age"; Nicholson, "Counting Culture; Or, How to Read Victorian Newspapers from a Distance"; Liddle, "Reflections on 20,000 Victorian Newspapers"; Brake, "Half Full and Half Empty"; Bingham, "'The Digitization of Newspaper Archives”; Steel, "Introduction."

2 Nicholson, "The Digital Turn"; Hitchcock, "Confronting the Digital”; Prescott, "I'd Rather Be a Librarian."

${ }^{3}$ See http://www.alicerap.eu Accessed 2/09/16.

${ }^{4}$ Hellman et al., Concepts of Addictive Substances and Behaviours Across Time and Place; Berridge et al., "Addiction Through the Ages: A Review of the Development of Concepts and Ideas About Addiction in European Countries since the Nineteenth Century and the Role of International Organisations in the Process"; Berridge, Mold, and Walke, "From Inebriety to Addiction: Terminology and Concepts in the UK, 1860-1930"; Berridge et al., "Addiction in Europe, 1860s1960s: Concepts and Responses in Italy, Poland, Austria and the United Kingdom."

${ }^{5}$ Snelders and Pieters, "Speed in the Third Reich"; Snelders, Pieters, and Meijman, "Alcoholism and Heredity in the Medical Sphere: The Netherlands 1850-1900"; Blok, "Pampering 'Needle Freaks' or Caring for Chronic Addicts?: Early Debates on Harm Reduction in Amsterdam"; Stephens, Germans on Drugs; Padwa, Social Poison.

${ }^{6}$ Porter, "The Drinking Man's Disease: The Pre History of Alcoholism in Georgian Britain."

${ }^{7}$ Levine, "The Discovery of Addiction: Changing Conceptions of Habitual Drunkenness in America."

8 Berridge, "Morality and Medical Science: Concepts of Narcotic Addiction in Britain, 1820-1926"; Harding, Opiate Addiction Morality and Medicine: From Moral Illness to Pathological Disease.

${ }^{9}$ Valverde, "Slavery from within': The Invention of Alcoholism and the Question of Free Will"; Valverde, Diseases of the Will: Alcohol and the Dilemmas of Freedom. 10 Berridge, "The Society for the Study of Addiction: Alcohol and Drug Treatment and Control L884-L988."

${ }^{11}$ Berridge, Mold, and Walke, "From Inebriety to Addiction: Terminology and Concepts in the UK, 1860-1930"; Moskalewicz and Herczyńska, "The Changing Meaning of Addiction in Polish Medical Literature of the Late Nineteenth Century and Early Twentieth Century"; Eisenbach-Stangl, "Passion and Insanity: A Twofold Concept of Addiction in Austria before World War Two"; Beccaria and Petrilli, "The Complexity of Addiction: Different Conceptualizations of Alcohol and Drug Addiction(s) among Italian Scholars in the Late 19th and Early 20th Century."

12 Berridge et al., "Addiction in Europe, 1860s-1960s: Concepts and Responses in Italy, Poland, Austria and the United Kingdom"; Mold et al., "Concepts of 
Addiction in Europe in the 1970s and 1980s: What Does a Long View Tell Us about Drugs, Alcohol and Tobacco?"

13 Beccaria and Petrilli, "The Complexity of Addiction: Different

Conceptualizations of Alcohol and Drug Addiction(s) among Italian Scholars in the Late 19th and Early 20th Century."

${ }^{14}$ Moskalewicz and Herczyńska, "The Changing Meaning of Addiction in Polish Medical Literature of the Late Nineteenth Century and Early Twentieth Century." 15 Eisenbach-Stangl, "Passion and Insanity: A Twofold Concept of Addiction in Austria before World War Two."

16 Eisenbach-Stangl; Moskalewicz and Herczyńska, "The Changing Meaning of Addiction in Polish Medical Literature of the Late Nineteenth Century and Early Twentieth Century"; Beccaria and Petrilli, "The Complexity of Addiction:

Different Conceptualizations of Alcohol and Drug Addiction(s) among Italian Scholars in the Late 19th and Early 20th Century."

17 This section draws on work published previously in Berridge et al., "Addiction in Europe, 1860s-1960s: Concepts and Responses in Italy, Poland, Austria and the United Kingdom."

18 Berridge, Mold, and Walke, "From Inebriety to Addiction: Terminology and Concepts in the UK, 1860-1930."

19 Beccaria and Petrilli, "The Complexity of Addiction: Different Conceptualizations of Alcohol and Drug Addiction(s) among Italian Scholars in the Late 19th and Early 20th Century."

${ }^{20}$ Eisenbach-Stangl, "Passion and Insanity: A Twofold Concept of Addiction in Austria before World War Two."

${ }^{21}$ Moskalewicz and Herczyńska, "The Changing Meaning of Addiction in Polish Medical Literature of the Late Nineteenth Century and Early Twentieth Century." ${ }^{22}$ Gutzke, "'The Cry of the Children': The Edwardian Medical Campaign against Maternal Drinking."

23 Beccaria and Petrilli, "The Complexity of Addiction: Different Conceptualizations of Alcohol and Drug Addiction(s) among Italian Scholars in the Late 19th and Early 20th Century," 48.

${ }^{24}$ Moskalewicz and Herczyńska, "The Changing Meaning of Addiction in Polish Medical Literature of the Late Nineteenth Century and Early Twentieth Century," 77.

${ }^{25}$ Beccaria and Petrilli, "The Complexity of Addiction: Different Conceptualizations of Alcohol and Drug Addiction(s) among Italian Scholars in the Late 19th and Early 20th Century."

${ }^{26}$ Seymour and Blaxill, "Adventures in Text Mining with the London MoH Annual Reports: Towards an Alternative History of Inter War Public Health."

\section{References}

Beccaria, Franca, and Enrico Petrilli. "The Complexity of Addiction: Different Conceptualizations of Alcohol and Drug Addiction(s) among Italian Scholars in the Late 19th and Early 20th Century." Social History of Alcohol and Drugs 28, no. 1 (2014): 34-56.

Berridge, Virginia. "Morality and Medical Science: Concepts of Narcotic Addiction in Britain, 1820-1926." Annals of Science 36 (1979): 67-85. 
- - " "The Society for the Study of Addiction: Alcohol and Drug Treatment and Control L884-L988." Addiction 85, no. 8 (1990): 983-1097.

Berridge, Virginia, Johan Edman, Alex Mold, and Suzanne Taylor. "Addiction Through the Ages: A Review of the Development of Concepts and Ideas About Addiction in European Countries since the Nineteenth Century and the Role of International Organisations in the Process," 2015.

http://www.alicerap.eu/about-alice-rap/areas-a-workpackages/area-1ownership-of-addiction.html.

Berridge, Virginia, Alex Mold, Franca Beccaria, Grazyna Herczyńska, Jacek Moskalewicz, Enrico Petrilli, and Suzanne Taylor. "Addiction in Europe, 1860s1960s: Concepts and Responses in Italy, Poland, Austria and the United Kingdom." Contemporary Drug Problems, forthcoming.

Berridge, Virginia, Alex Mold, and Jennifer Walke. "From Inebriety to Addiction: Terminology and Concepts in the UK, 1860-1930." Social History of Alcohol and Drugs 28, no. 1 (2014): 88-106.

Bingham, Adrian. "'The Digitization of Newspaper Archives: Opportunities and Challenges for Historians.'” Twentieth Century British History 21, no. 2 (2010): 225-31. https://doi.org/10.1093/tcbh/hwq007.

Blok, Gemma. "Pampering 'Needle Freaks' or Caring for Chronic Addicts?: Early Debates on Harm Reduction in Amsterdam." Social History of Alcohol and Drugs 22, no. 2 (2008): 243-61.

Brake, Laurel. "Half Full and Half Empty." Journal of Victorian Culture 17, no. 2 (June 1, 2012): 222-29. https://doi.org/10.1080/13555502.2012.683149.

Eisenbach-Stangl, Irmgard. "Passion and Insanity: A Twofold Concept of Addiction in Austria before World War Two." Social History of Alcohol and Drugs 28, no. 1 (2014): 9-33.

Gutzke, David. "'The Cry of the Children': The Edwardian Medical Campaign against Maternal Drinking." British Journal of Addiction 79, no. 1 (1984): 71-84.

Harding, Geoffrey. Opiate Addiction Morality and Medicine: From Moral Illness to Pathological Disease. Basingstoke: Macmillan, 1988.

Hellman, Matilda, Virginia Berridge, Karen Duke, and Alex Mold. Concepts of Addictive Substances and Behaviours Across Time and Place. Oxford University Press, 2016.

Hitchcock, Tim. "Confronting the Digital." Cultural and Social History 10, no. 1 (March 1, 2013): 9-23. https://doi.org/10.2752/147800413X13515292098070.

Levine, Harry Gene. "The Discovery of Addiction: Changing Conceptions of Habitual Drunkenness in America." Journal of Studies on Alcohol 39 (1978): 14374. 
Liddle, Dallas. "Reflections on 20,000 Victorian Newspapers: 'Distant Reading' The Times Using The Times Digital Archive." Journal of Victorian Culture 17, no. 2 (June 1, 2012): 230-37. https://doi.org/10.1080/13555502.2012.683151.

Mold, Alex, Franca Beccaria, Virginia Berridge, Irmgard Eisenbach-Stangl, Grazyna Herczyńska, Jacek Moskalewicz, Enrico Petrilli, and Suzanne Taylor. "Concepts of Addiction in Europe in the 1970s and 1980s: What Does a Long View Tell Us about Drugs, Alcohol and Tobacco?" In Concepts of Addictive Substances and Behaviours Across Time and Place, edited by Matilda Hellman, Virginia Berridge, Karen Duke, and Alex Mold. Oxford: Oxford University Press, 2016.

Moskalewicz, Jacek, and Grazyna Herczyńska. "The Changing Meaning of Addiction in Polish Medical Literature of the Late Nineteenth Century and Early Twentieth Century." Social History of Alcohol and Drugs 28, no. 1 (2014): 57-87.

Mussell, James. "Nineteenth-Century Newspapers in the Digital Age." Journal of Victorian Culture 17, no. 2 (June 1, 2012): 221-221. https://doi.org/10.1080/13555502.2012.683147.

Nicholson, Bob. "Counting Culture; or, How to Read Victorian Newspapers from a Distance." Journal of Victorian Culture 17, no. 2 (June 1, 2012): 238-46. https://doi.org/10.1080/13555502.2012.683331.

. “The Digital Turn.” Media History 19, no. 1 (February 1, 2013): 59-73. https://doi.org/10.1080/13688804.2012.752963.

Padwa, Howard. Social Poison: The Culture and Politics of Opiate Control in Britain and France, 1821-1926. 1 edition. Baltimore: Johns Hopkins University Press, 2012.

Porter, Roy. “The Drinking Man's Disease: The Pre History of Alcoholism in Georgian Britain." British Journal of Addiction 80 (1985): 385-96.

Prescott, Andrew. "I'd Rather Be a Librarian." Cultural and Social History 11, no. 3 (September 1, 2014): 335-41.

https://doi.org/10.2752/147800414X13983595303192.

Seymour, Jane, and Luke Blaxill. "Adventures in Text Mining with the London MoH Annual Reports: Towards an Alternative History of Inter War Public Health." presented at the London Health Histories, Wellcome Trust, London, June 17, 2016. http://blog.wellcomelibrary.org/2016/05/london-health-histories-aworkshop/.

Snelders, Stephen, and Toine Pieters. "Speed in the Third Reich:

Metamphetamine (Pervitin) Use and a Drug History From Below." Social History of Medicine 24, no. 3 (December 1, 2011): 686-99.

https://doi.org/10.1093/shm/hkq101.

Snelders, Stephen, Toine Pieters, and Frans Meijman. "Alcoholism and Heredity in the Medical Sphere: The Netherlands 1850-1900." Social History of Alcohol and Drugs 22, no. 2 (2008): 130-43. 
Steel, John. "Introduction." Media History 20, no. 1 (January 2, 2014): 1-3. https://doi.org/10.1080/13688804.2013.872410.

Stephens, Robert P. Germans on Drugs: The Complications of Modernization in Hamburg. Ann Arbor: University of Michigan Press, 2007.

Valverde, Mariana. Diseases of the Will: Alcohol and the Dilemmas of Freedom. Cambridge: Cambridge University Press, 1998.

Free Will." Social History 22, no. 3 (1997): 251-68. 